\title{
Survival of Wheat Curl Mites on Different Sources of Resistance in Wheat
}

\author{
T. L. Harvey, D. L. Seifers, T. J. Martin,* G. Brown-Guedira, and B. S. Gill
}

\begin{abstract}
Wheat (Triticum aestivum L.) yield is limited by wheat streak mosaic virus which is vectored by the wheat curl mite (WCM) Aceria tosicheilla (Keifer). Host resistance to WCM has reduced losses. This study was conducted to evaluate the effectiveness of resistance in wheat to WCM collected from various locations in the Great Plains. Collections of WCM from Montana, Nebraska, South Dakota, Texas, Alberta, Canada, and eight locations in Kansas were compared for their ability to survive and reproduce in the greenhouse on seven lines of wheat and wheat relatives previously identified as resistant. The lines and their sources of resistance were: AC PGR16635 (Aegilops tauschii Coss., Cmc1), PI 525452 (Thinopyrum ponticum (Podp.) Liu and Wang, Cmc2), KS96WGRC40 (Ae. tauschii and Secale cereale L.), TA920 (Triticum timopheevii (Zhuk.) Zhuk spp. armenidcum ), PI 475772 (S. cereale), 'TAM 107' (S. cereale), PI 222655 (T. aestivum ). KS96WGRC40 and TA920 were the only entries that were resistant to all WCM collections. Other sources of resistance were effective against WCMs from some but not all locations. PI 222655 was resistant to WCMs from Nebraska and central Kansas but not to mites from most other locations. WCMs that were virulent to TAM 107 generally were also virulent to PIs 222655 and 475772 but avirulent to $\mathrm{Cmc2}$. The WCMs from western Kansas, where TAM 107 is widely grown, were generally more virulent to that cultivar than WCM from central Kansas where the hectarage of TAM 107 is smaller. WCMs collected at different times or locations may vary in their responses to different sources of resistance; therefore, testing mites for their response to resistance genes advanced in breeding programs may be needed before resistant cultivars are deployed in the field.
\end{abstract}

$\mathrm{W}$ HEAT STREAK MOSAIC, caused by wheat streak mosaic virus (WSMV) and vectored by the wheat curl mite (WCM), Aceria tosichella, is the most important disease of wheat in western Kansas. Resistant wheat that inhibits reproduction of the WCM has effectively reduced the incidence of WSM (Martin et al., 1984; Harvey and Martin, 1988; Harvey et al., 1990; Conner et al., 1991). A WCM-resistant cultivar, TAM 107, has been grown widely in western Kansas since 1988, but the WCM has been able to overcome its resistance in both the field and greenhouse (Harvey et al., 1995b, 1997). TAM 107 derives its WCM resistance from the 'Amigo' 1RS/1AL translocation from rye, S. cereale (Sebesta et al., 1994; Wood et al., 1995). Additional sources of WCM resistance have been identified and most have been transferred to common wheat (Table

T.L. Harvey, Dep. of Entomology, Kansas State Univ., Hays, KS 67601; D.L. Seifers and T.J. Martin, KSU Agric. Res. Center, Hays, KS 67601; G. Brown-Guedira, USDA, ARS, Dep. of Agronomy, Kansas State Univ., Manhattan, KS 66506; and B.S. Gill, Wheat Genetics Resources Center, Dep. Plant Pathology, Kansas State Univ., Manhattan, KS 66506. Research supported in part by a grant from the Kansas Wheat Commission. Contribution no. 98-446-J of Kansas Agric. Exp. Stn. Mention of a proprietary product does not constitute a recommendation or endorsement by Kansas State University. Received 1 June 1998. *Corresponding author (jmartin@oz.oznet. ksu.edu).

Published in Crop Sci. 39:1887-1889 (1999).
1). PI 222655 is the only source in Table 1 that originated in common wheat.

These WCM-resistance sources have not been utilized commercially, but some are being advanced in wheat breeding programs. As different collections of WCM vary in degree of virulence to resistant wheat (Harvey et al., 1995a), it is important to evaluate the range in response among WCM strains collected from areas for which resistant cultivars are targeted. The objective of this research was to expand on a previous report (Harvey et al., 1995a) by using a wider range of WCM cultures to evaluate the effectiveness of resistance provided by the previously tested resistant sources and two recently identified sources of resistance.

\section{MATERIALS AND METHODS}

Sources of WCM-resistant germplasm are given in Table 1. The wheat cultivar Larned, (CI 17650) was used in all tests as a WCM-susceptible control (Harvey et al., 1998). Host resistance is defined herein as the ability to reduce WCM reproduction to significantly $(P=0.05)$ less than reproduction on Larned. Virulence or avirulence to a host refers to the mite's ability to reproduce on that host relative to reproduction on the susceptible control.

Collections of WCM from Kansas included several hundred mites originally obtained from unknown cultivars in commercial wheat fields. Ten tillers (Feekes 4-5) or spikes (Feekes 10.7) of wheat were sampled from one field from each of eight counties. The leaves or spikes collected from the field were placed in contact with Larned wheat plants (two-leaf stage) established in poly-cast tubes, $2.5 \mathrm{~cm}$ in diameter and $14 \mathrm{~cm}$ long (Stuewe and Sons, Inc., Corvallis, OR) containing a standard greenhouse soil mixture. The seedlings were covered with cylinder cages made from $25-$ by $300-\mathrm{mm}$ clear plastic tubing (Sinclair and Rush Co., St. Louis, MO). Each cage was vented with eight, $12-\mathrm{mm}$-diam. openings that were covered with nylon mesh with16- $\mu$ m-diam. openings (3-35/16xx; H.R. Williams Mill Supply Co., Kansas City, MO). This cage provided an effective barrier against passage of the smallest WCM and served to isolate and maintain the purity of the populations (Seifers et al., 1997). The plant material collected from the field was placed in the cages in contact with the Larned seedlings. As the field plants wilted and dried the WCMs transferred to the caged plants. After the WCM colonies were established they were reared for several generations on caged Larned seedlings maintained in a greenhouse $\left(27 \pm 10^{\circ} \mathrm{C}\right)$ before being used in experiments.

The WCM collections from Ellis and Barton counties in Kansas were obtained from tillers of volunteer wheat in October 1996 and 1997, respectively. The WCMs from Dickinson, Ellsworth, Finney, Geary, Greeley, and Saline counties were collected from wheat spikes during May and June, 1997. Barton, Ellis, Finney and Greeley counties are in western Kansas and Dickinson, Ellsworth, Geary, and Saline counties are in central or eastern Kansas. The WCM colonies obtained from Montana, Nebraska, South Dakota, and Texas were provided in 1996 by Drs. Sue Blodgett, Talat Mohamood, Robert Collins, and Charles Rush, respectively. The WCM collection from Alberta, Canada, was provided in 1997 by Dr. Robert 
Table 1. Sources of resistance to wheat curl mite and their origin.

\begin{tabular}{|c|c|c|c|}
\hline Designation $\dagger$ & Triticum species & Source of wheat curl mite resistance & Reference \\
\hline PI 222655 & aestivum & Triticum aestivum & Harvey and Martin, 1992 \\
\hline ACPGR 16635 & aestivum & Aegilops tauschii (Cmc1) & Thomas and Conner, 1986 \\
\hline PI 525452 & aestivum & Thinopyrum ponticum (Cmc2) & Whelan and Conner, 1989 \\
\hline TA 920 & timopheevii & Triticum timopheevii var. armeniacum & Harvey, unpublished data \\
\hline KS96WGRC40 & aestivum & Aegilops tauschii and Secale cereale (TAM 107) & Cox et al., 1999 \\
\hline PI 475772 & aestivum & Secale cereale & Martin et al., 1983 \\
\hline ТАМ 107 & aestivum & Secale cereale & Sebesta et al., 1994 \\
\hline Larned & aestivum & None & Harvey et al., 1998 \\
\hline
\end{tabular}

$\dagger$ PI 525452 is also known as LRS-7-50. PI 475772 is also known as KS80H4200. TAM 107 has the USDA accession number PI 495594 and Larned has the USDA accession number CItr 17650.

Conner. All colonies were maintained and reared as previously described for the Kansas collections. The identity of WCMs used in this study as Aceria tosichella was confirmed by J.W. Amrine (West Virginia University, Morgantown). Voucher specimens, No. 092, are deposited in the Research Collection of Insects, Dep. of Entomology, Kansas State University.

Single seedlings of each genotype in Table 1 were established in poly-cast tubes and covered with cylinder cages as previously described. Five seedlings per accession infested with 10 WCMs per seedling constituted a replication. The WCMs were transferred from the rearing host to the test plants at the two-leaf stage by placing infested leaf clippings from Larned plants in 2-mL shell vials. As the leaves dehydrated, the WCMs crawled onto the lip of the vial, where they were picked up on the tip of a hair glued to a dowel and released into the whorl of the second leaf of each test plant. Only adults or second instars displaying normal movement were used. The WCMs were transferred and counted by means of a dissecting microscope with $20 \times$ magnification and a fiber optic system to provide cold light.

Immediately after infestation the caged plants were completely randomized into supportive racks, set in watering trays, and held on a greenhouse bench with natural light and variable temperatures $\left(27 \pm 10^{\circ} \mathrm{C}\right)$. Because WCMs can complete a generation in less than $10 \mathrm{~d}$, seedlings were excised and examined 7 to $8 \mathrm{~d}$ after infestation to determine the number of WCMs per plant. Plants were completely unrolled and dissected to ensure that all mites were recorded. Infestation periods longer than $8 \mathrm{~d}$ allow WCM numbers to become too large on susceptible hosts to be counted easily. Five seedlings of each of the eight test entries infested at one time with one WCM collection constituted a test. Each test was repeated three times for each WCM collection. Tests were conducted during October and November 1997 with variable time periods between replications.

Numbers of WCMs per plant for each entry were subjected to analysis of variance. Treatment means were separated by the Student-Newman-Keuls (Steel and Torrie, 1960) multiple range test at $P=0.05$. Entries on which WCM numbers were found to be significantly lower than those recorded on Larned were considered to be resistant.

\section{RESULTS AND DISCUSSION}

The WCMs collected from different counties in Kansas varied in their reproductive responses to the different entries (Table 2). KS96WGRC40 and TA920 were the only lines on which WCM from all collections reproduced significantly less than on Larned. However, the reaction of the WCM collections tested here do not provide any evidence that the gene derived from Aegilops tauschii in KS96WGRC40 is different from Cmc1. Although WCMs from Greeley and Ellsworth counties were virulent to $\mathrm{Cmcl}$ and avirulence to KS96WGRC40 this can be explained by their avirulence to the TAM 107 derived wheat-rye translocation in KS96WGRC40. The WCM collections from Ellis and Finney counties were avirulent to all lines except PI 222655, PI 475772 and TAM 107. The WCM response generally did not differ for the two rye sources of resistance (PI475772 and TAM 107), except that PI 475772 was significantly more resistant than TAM 107 to the collection from Ellis county.

In a previous study by Harvey et al. (1997), WCMs collected from 14 western Kansas counties during May and June 1995 were virulent to TAM 107. In the present study, WCMs collected from two western Kansas counties (Ellis and Finney) were virulent to TAM 107, but five collections from eastern Kansas (Barton, Dickinson, Ellsworth, Geary, and Saline) were avirulent. This may be explained by additional selection pressure induced by widespread production of TAM 107 in western Kansas. However, WCMs from South Dakota also were virulent to TAM 107 (Table 3), although it is not commonly grown there.

Table 2. Mean number of wheat curl mites per plant on previously reported WCM resistant genotypes after 8 d incubation with mites collected from eight counties in central and west Kansas.

\begin{tabular}{|c|c|c|c|c|c|c|c|c|}
\hline \multirow[b]{2}{*}{ Wheat line or cultivar } & \multicolumn{5}{|c|}{ Central $\dagger$} & \multicolumn{3}{|c|}{ West $\dagger$} \\
\hline & GE & DK & SA & EW & BT & $\mathbf{E L}$ & FI & GL \\
\hline PI 222655 & $3 \mathbf{c} \dagger \dagger$ & 1c & 1c & $\mathbf{0 b}$ & $\mathbf{1 b}$ & 41ab & 43a & $3 \mathbf{c}$ \\
\hline ACPGR 16635 ( $\mathrm{Cmcl})$ & $68 \mathrm{a}$ & $11 b$ & $18 b$ & $37 \mathbf{a}$ & $11 b$ & $7 c$ & $16 b$ & $33 b c$ \\
\hline PI 525452 (Cmc2) & 88a & 43a & $40 a$ & 33a & 30a & $12 \mathrm{c}$ & $17 \mathbf{b}$ & 46ab \\
\hline ТА 920 & $29 b$ & 15b & $9 \mathrm{bc}$ & $9 b$ & $\mathbf{4 b}$ & $9 \mathrm{c}$ & $\mathbf{5 b}$ & $31 b c$ \\
\hline KS96WGRC40 & $15 \mathrm{bc}$ & $2 c$ & $16 b$ & $\mathbf{8 b}$ & $\mathbf{1 b}$ & $8 c$ & 12b & $13 c$ \\
\hline PI 475772 & 19bc & $2 c$ & $12 b c$ & 11b & $\mathbf{6 b}$ & $38 b$ & $47 \mathbf{a}$ & $30 b c$ \\
\hline ТАМ 107 & $19 b c$ & $1 c$ & $13 \mathrm{bc}$ & $15 b$ & $7 b$ & $51 a$ & $60 a$ & $24 b c$ \\
\hline Larned & $86 a$ & $45 \mathbf{a}$ & $48 a$ & $41 a$ & $37 \mathbf{a}$ & 45ab & $56 a$ & $60 a$ \\
\hline
\end{tabular}

$\dagger$ County of collection: GE $=$ Geary, DK $=$ Dickinson, $\mathbf{S A}=$ Saline, $\mathbf{E W}=$ Ellsworth, BT $=$ Barton, EL $=$ Ellis, FI $=$ Finney, GL $=$ Greeley.

$\dagger$ Means (three tests) within a column followed by the same letter are not significantly different $(P=0.05)$. 
Table 3. Mean number of wheat curl mites per plant on previously reported WCM resistant genotypes after $8 \mathrm{~d}$ incubation with mites collected from five states and Alberta, Canada (AB).

\begin{tabular}{|c|c|c|c|c|c|}
\hline Wheat line or cultivar & MT & NE & SD & $\mathbf{T X}$ & $\mathbf{A B}$ \\
\hline & & & no. & & \\
\hline PI 222655 & $43 \mathbf{a} \dagger$ & $6 c$ & $66 a$ & 47a & 25b \\
\hline ACPGR 16635 ( $\mathrm{Cmcl})$ & $10 b c$ & $55 \mathbf{a}$ & 17d & $14 c$ & $5 d$ \\
\hline PI 525452 (Cmc2) & $15 b$ & $70 a$ & $26 c$ & 33b & $15 \mathrm{c}$ \\
\hline TA 920 & $10 b c$ & $21 b c$ & 35b & $17 \mathrm{c}$ & 1d \\
\hline KS96WGRC40 & 2c & $22 b c$ & 18d & 14c & 1d \\
\hline PI 475772 & 1c & $21 b c$ & $67 a$ & 53a & 2d \\
\hline TAM 107 & 3c & 30b & $69 a$ & $57 \mathbf{a}$ & 2d \\
\hline Larned & $47 \mathbf{a}$ & $71 a$ & $74 a$ & 57a & 42a \\
\hline
\end{tabular}

$\uparrow$ Means (three tests) within a column followed by the same letter are not significantly different $(P=\mathbf{0 . 0 5})$.

As reported for WCMs collected from Kansas, KS96WGRC40 and TA920 were the only lines that were resistant to all collections from Montana, Nebraska, South Dakota, Texas, and Alberta (Table 3). Wheat lines having the genes $C m c 1$ and $C m c 2$ were resistant to all collections except those from Nebraska. ACPGR $16635(\mathrm{Cmcl})$ was more resistant than PI $525452(\mathrm{Cmc} 2)$ to collections from South Dakota, Texas, and Alberta. PI 222655 was only resistant to collections from $\mathrm{Ne}$ braska and Alberta. The reaction of all WCM collections (Tables 2 and 3) to PI 222655 was the reverse of that to PI 525452 ( $\mathrm{Cmc} 2$ ). The rye sources of resistance, PI 475772 and TAM 107, were susceptible to WCMs from South Dakota and Texas but resistant to collections from Montana, Nebraska, and Alberta.

Collections of WCMs from Texas, South Dakota, and Alberta in 1994 were tested previously for survival on ACPGR16635, PI 525452, PI 222655, PI 475772, and TAM 107 (Harvey et al., 1995a). The cultivar Tomahawk was used as the susceptible control in the previous study and Larned was the control in this study. However, comparisons between the two studies are valid because WCM reproduction on the two cultivars do not differ significantly (Harvey, 1993, unpublished data). The WCMs collected from Alberta in 1994 and those used in this study reacted similarly to the available genotypes. However, the WCMs collected from South Dakota, and Texas in 1994 were markedly different from those evaluated in this study. For example, all sources were resistant to WCMs collected from South Dakota in 1994, but the 1996 South Dakota collection was virulent to PI 222655 , PI 475772, and TAM 107. The 1994 Texas collection was virulent to ACPGR 16635 ( Cmcl) and PI 525452 $(\mathrm{Cmc})$ and avirulent to PI 222655, PI 475772 and TAM 107, but the opposite was recorded for WCMs collected from Texas in 1996 (Table 3). The WCMs collected at different times or locations in South Dakota and Texas, like those reported for Kansas, may vary in their responses to different sources of resistance due to changes in virulence or to differences in sampling techniques.

For reasons not well understood, the only WCM collections from Kansas that were virulent to TAM 107 (Ellis and Finney) also were the only collections virulent to PI 222655 and avirulent to PI 525452 ( $\mathrm{Cmc} 2$ ) (Table 2 ). This relationship held for collections from other states (Table 3), except for WCMs from Montana, which were avirulent to both PI 525452 ( $\mathrm{Cmc}$ ) and TAM 107 and virulent to PI 222655.
In Kansas, and probably other states, WCMs can be highly variable in their ability to survive on genotypes that were selected for resistance. Testing of WCMs collected at different times and locations on resistance sources being advanced in breeding programs may be needed before resistant cultivars are deployed in the field. The use of multiple sources of resistance in the same line may also be needed as in KS96WGRC40. The wild tetraploid wheat accession T. timopheevii (TA920) appears to be the most consistently resistant source currently available, but WCMs now avirulent to it may become virulent as it is deployed, as occurred previously with TAM 107 in western Kansas. However, TAM 107 provided useful protection against WSMV for several years before its effectiveness declined because of increased virulence of WCMs.

\section{REFERENCES}

Conner, R.L., J.B. Thomas, and E.D.P. Whelan. 1991. Comparison of mite resistance for control of wheat streak mosaic. Crop Sci. 31:315-318.

Cox, T.S., B.S. Gill, W.W. Bockus, R.G. Sears, T.L. Harvey and S. Leath. 1999. Registration of KS96WGRC40 wheat germplasm resistant to wheat curl mite, stagonospora leaf blotch, and septoria leaf blotch. Crop Sci. 39:597

Harvey, T.L., and T.J. Martin. 1988. Sticky-tape method to measure cultivar effect on wheat curl mite (Acari:Eriophyidae) populations in wheat spikes. J. Econ. Entomol. 81:731-734.

Harvey, T.L., T.J. Martin, and D.L. Seifers. 1990. Wheat curl mite and wheat streak mosaic in moderate trichome density wheat cultivars. Crop Sci. 30:534-536.

Harvey, T.L., and T.J. Martin. 1992. Resistance to the wheat curl mite (Acari:Eriophyidae) in common wheat. Cereal Res. Commun. 20:63-66.

Harvey, T.L., T.J. Martin, and D.L. Seifers. 1995a. Survival of five wheat curl mite, Aceria tosichilla Keifer (Acari:Eriophyidae) strains on mite resistant wheat. Exp. and Appl. Acarol. 19:459-463.

Harvey, T.L., T.J. Martin, D.L. Seifers, and P.E. Sloderbeck. 1995 b. Adaptation of a wheat curl mite (Acari:Eriophyidae) to resistant wheat in Kansas. J. Agric. Entomol. 12:119-125.

Harvey, T.L., T.J. Martin, D.L. Seifers, and P.E. Sloderbeck. 1997. Change in virulence of wheat curl mite detected on TAM 107 wheat. Crop Sci. 37:624-625.

Harvey, T.L., D.L. Seifers, and T.J. Martin. 1998. Effect of Imidacloprid seed treatment on infestations of wheat curl mites (Acari: Eriophyidae) and the incidence of wheat streak mosaic. J. Agric. Entomol. 15:75-81.

Martin, T.J., T.L. Harvey, C.G. Bender, and D.L. Seifers. 1984. Control of wheat streak mosaic virus with vector resistance in wheat Phytopathology 74:963-964.

Martin, T.J., T.L. Harvey, C.G. Bender, D.L. Seifers, and J.H. Hatchett. 1983. Wheat curl mite resistant wheat germplasm. Crop Sci 23:809

Sebesta, E.E., E.A. Wood, Jr., D.R. Porter, J.A. Webster, and E.L. Smith. 1994. Registration of Gaucho greenbug-resistant triticale germplasm. Crop Sci. 34:1428.

Seifers, D.L., T.L. Harvey, T.J. Martin, and S.G. Jensen. 1997. Identification of the wheat curl mite as the vector of the high plains virus of corn and wheat. Phytopathology 81:1161-1166.

Steel, R.G.D., and J.H. Torrie. 1960. Principles and procedures of statistics. McGraw-Hill, New York.

Thomas, J.B., and R.L. Conner. 1986. Resistance to colonization by the wheat curl mite in Aegilops squarrosa and its inheritance after transfer to common wheat. Crop. Sci. 26:527-530.

Whelan, E.D.P., and G.E. Hart. 1988. A spontaneous translocation that transfers wheat curl mite resistance from decaploid Agropyron elongatum to common wheat. Genome 30:289-292.

Wood, E.A. Jr., E.E. Sebesta, J.A. Webster, and D.R. Porter. 1995. Resistance to wheat curl mite (Acari:Eriophyidae) in greenbugresistant 'Gaucho' triticale and 'Gaucho' $\times$ wheat crosses. J. Econ. Entomol. 88:1032-1036. 